EREM 76/3

Journal of Environmental Research, Engineering and Management Vol. 76 / No.3 / 2020 pp. $109-120$ DOI 10.5755/j01.erem.76.3.25204

\section{Remote Sensing Monitoring of Biotopes Distribution within} Nature Reserve Area

Accepted after revision 2020/08

\title{
Remote Sensing Monitoring of Biotopes Distribution within Nature Reserve Area
}

\section{O.Trofymchuk, S. Zagorodnya, N. Sheviakina*, I. Radchuk}

Institute of Telecommunications and Global Information Space of the National Academy of Sciences of Ukraine, 13, Chokolovskiyblv., Kyiv, Ukraine

\section{Tomchenko}

State institution "Scientific Centre for Aerospace Research of the Earth of the Institute of Geological Science of the National Academy of Sciences of Ukraine", 55-b, 0. Gonchar str., Kyiv, Ukraine

*Corresponding author: n.a.sheviakina@gmail.com

The core of renewable natural resources of any nation is its natural reserve fund. The issue of natural ecosystems preserving is becoming more and more actual at the present stage in terms of increasing human influence on the environment. The article presents models of assessment and analysis of the environmental state of nature reserves combining remote and ground-based methods of research. The natural resources potential and biotope distribution within Biloozerskyi site of Rivne Nature Reserve were analyzed based on the Earth Remote Sensing data in order to ensure the preservation of background environmental indicators. The technology of cartographic provision for assessment and analysis of the environmental condition of natural protected areas by means of geoinformation technologies providing interpretation of the results of analysis in a graph form on electronic maps was considered.

Keywords: nature reserve, environmental monitoring, remote sensing, geoinformation technologies, background monitoring. 


\section{Introduction}

The issue of monitoring protected areas is pressing in any part of our planet. In order to increase and preserve biological and landscape diversity, it is necessary to have comprehensive information on the state and dynamics of the research object change, which is a certain local ecosystem. A lot of the necessary information is given by ground-based observations of the subject under research. However, this information is almost always not enough to make optimal decisions, in particular regarding forest and wetland landscapes that are important but not available for direct observation. In terms of obtaining additional but often unified and basic information, the most promising and effective is the observation of natural areas from outer space. A satellite image is an independent reliable source of information as for the lands of the natural reserve fund state and has the greatest effect in solving the following tasks: definition of the area and the territorial placement of objects; operative assessment of the state of nature-protected objects; creation of databases for species and landscape diversity inventory and effective environmental management; identification of the territory where the most adverse impact on the natural environment occurs; and identification of areas of conflict between different users.

Despite active development of information technologies, the issues of environmental monitoring of nature reserve areas are paid relatively little attention. The main priority is given to field studies of ecosystems and their components (Dovgyi et al., 2018). During assessment of protected areas as complex ecosystems, the specifics of genetically united, interconnected biocenoses, valuable landscape complexes, and transboundary territories should be taken into account. Research data are in various organizations, stored in various formats, which makes it difficult to use them in a comprehensive way (Armenakis et al., 2014). The involvement of information technologies for the study of nature reserve areas, their morphology and components at the modern scientific and technical level is an important task for addressing the issues related to nature conservation and recreational and economic functions of nature reserves and adjoining territories (Jonson et al., 2002).

\section{Methods}

State-of-the-art

Nature reserve areas provide for the restoration of biotopes, protection of endangered species, vulnerable, key or complex species. Scientific research in the nature reserve fund (NRF) areas changes along with the development of science, extends knowledge of nature and change of the environmental situation in the country and its separate regions. Many works by famous scientists regarding this issue have been published. However, it requires scientific evidence of the use of techniques that can be applied during the study of areas and places requiring special protection, based on available technical and methodological base. Scientific and methodological principles of creation and application of information technology for use in the fields of environmental management, natural resources, and environmental protection is revealed in the works by Lyalko, Popov, Dovgyi, Trofimchuk, Krasowski, Fedorovsky (Dovhyiet al., 2001) and others. Particular attention should be paid to the use of the Earth Remote Sensing and GIS technologies in the assessment of natural ecosystems (Armenakis and Siekierska, 2009).Scientists in the reviewed publications have proposed the use of remote sensing methods, a geographic information system and mathematical modeling for assessing nature reserves. However, when assessing conservation areas as complex ecosystems, a comprehensive environmental assessment should be made and the specifics of genetically combined, interconnected biocenoses, as well as valuable landscape complexes should be taken into account.

That is why the authors of this article pay great attention to improving the information and analytical tools for assessing the ecological state of nature reserves for high-quality background monitoring of the environment.

\section{Objective and task}

The objectives of this work are:

1 To improve the scientific and methodical basis as well as information and analytical instruments of assessment of the ecological condition of nature reserves, which are grounded on decrypting satellite images using the method of artificial neural network. 
2 To develop aninformational database of a natural resource potential for a studied territory ecosystem services assessment.

3 To create mapping models of research results, territorial analysis by anthropogenic influence indexes.

\section{Research methods}

Satellite images can be successfully used to address the issues of the study ofthe nature reserve area state. They are used for background monitoring, i.e., inventory and operational mapping of natural resources, phenological and dynamic monitoring, i.e., observation of seasonal and perennial changes in the natural environment, as well as to assess the impact of anthropogenic activities on the natural environment, control over the size, shape, depth and impact from economic activities. In order to successfully accomplish the tasks set for the research of nature reserve objects, images archives of satellites Landsat, Sentinel, WorldView-2 etc. are used. Spatial differentiation from several decimeters to several hundred meters allows us to study the multi-year dynamics of natural complexes in the nature reserve areas (Trofymchuk et al., 2014).

Today, a rather great number of remotely sensed data satellites are being operated with the devices providing the Earth observation in optical and IR spectrum on the above satellites. Landsat software is one of the oldest in creation and use of remotely sensed data space systems and contains the longest timing series of archive satellite images since 1972. Landsat 5, 7 and 8 free data are shared through USGS service (earthexplorer.usgs.gov). That is why the Landsat satellite images are basic in our research.

Nowadays, there is a lot of applicable software of different levels for remotely sensed data and image processing starting from distributed free to expensive highly professional ones. The software allows implementingthe wide spectrum of processing, visualization, analysis and use of geographical information. Erdas Imagine, ArcGis 10 and QGis software packages were used for processing and interpretation of remote sensing data. The packages are built according to the module hierarchical principle and the decision is scaled, the efficiency of which depends on the user requirements for the image processing process (Trofymchuk et al., 2015). The above software product tools were involved into the work with the satellite images during the nature reserve areas survey.

The process of satellite image processing consists of stages presented in Fig.1. Most notably, of the

Fig. 1. The block diagram of the assessment of the ecological state of nature reserves using remotely sensed data

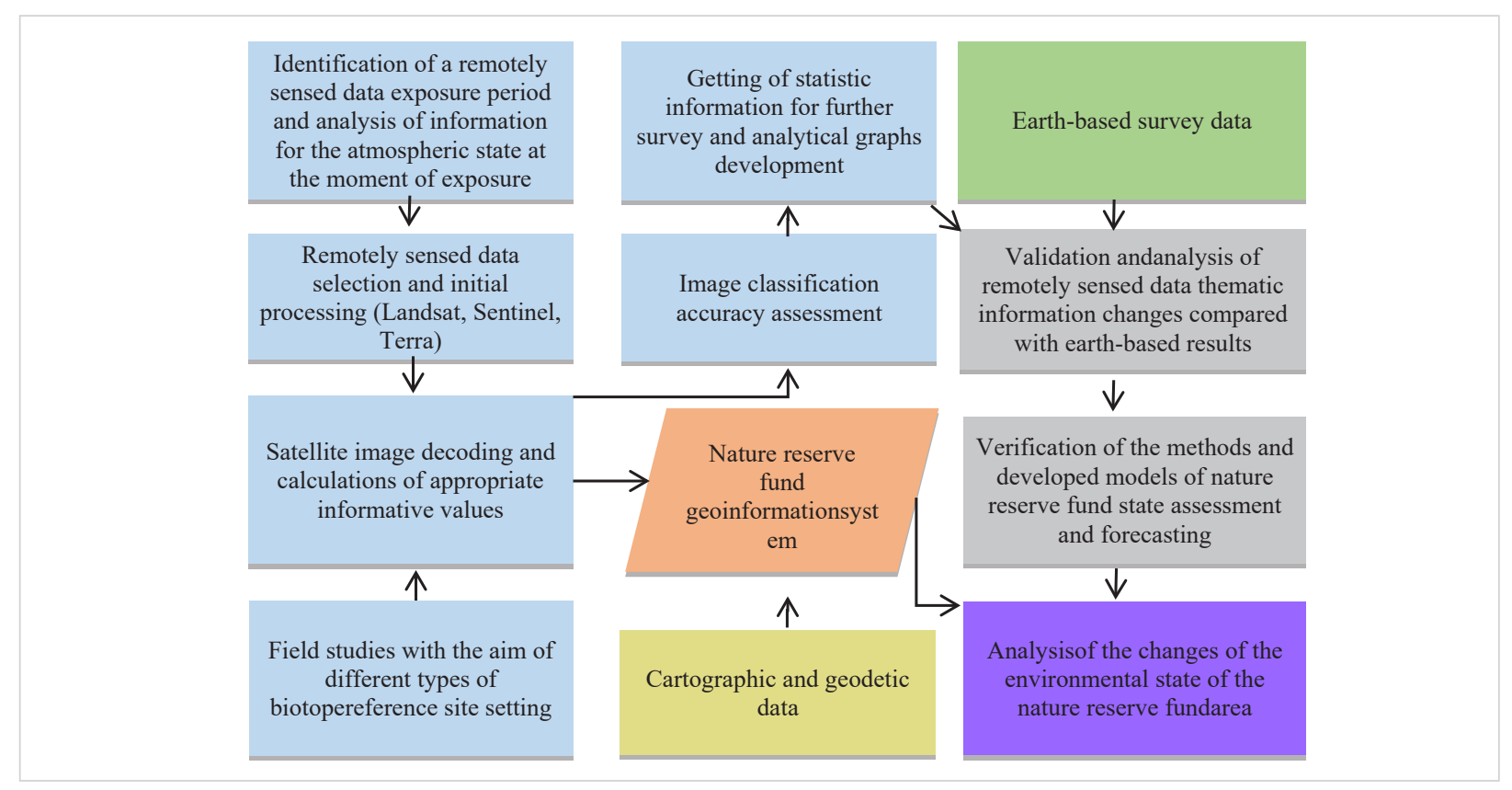


exposure period required to identify area under survey, select remotely sensed data with required resolution, using software products for statistic calculation, a- build an analytical graph and validate the accuracy acquired values compared to the earth based results, and load obtained information into geoinformation system with further ability to get necessary information using GIS technical tools (Tomchenko, 2015).

\section{Results and Discussion}

Presentation of basic material and the research findings

Research of Rivne nature reserve area was taken as an example possibilities complex application of GIS and remotely sensed data technologies. The above object is the second largest nature reserve in Ukraine with an area of 47,047 ha. The territory of the nature reserve is located in four districts of Rivneregion, i.e., Volodymyrets, Sarny, Rokytne and Dubrovytsia, and has four separate areas "Biloozerskyi", "Somyne", "Perebrody" and "SyraPogonya". Direct research was carried out on Biloozerskyi area. The peculiarity of the above area is bogs typical for the Western Polissia region (Koza-Berezyna bog) and one of the largest karst lakes in Polissia (Bile lake is $453 \mathrm{ha}$ ). These objects could potentially be included in the list of Ramsar Convention. There is a recreation zone with a camping site on Bile lake with a significant anthropogenic impact resulting in accumulation of a huge volume of waste and ecosystem failure (Nature Records of Rivne Nature Reserve, 2015).

Therefore, there is a need to create a single database of environmental parameters and anthropogenic factors of the area to serve as a tool for scientific, research and management tasks. The obtained complex of electronic environmental and cartographic data will reflex the biotope state of the area, its relief, hydrological network, recreation zones, landscapes, sites of wetlands, digital maps of forest planting with appropriate mensuration description and alphanumeric data regarding species demanding special protection (Fedra, 2006).
Medium resolution images from Landsat 5 with TM (Thematic Mapper) scanner and Landsat 8 with TIRS (Thoermallnfrared Sensor) and OLI (Operational Land Imager) scanners in exposure modes: VNIR (Visible and Near Infrared), SWIR (Shortwave Infrared) were chosen for retrograde and modern analysis of the specified nature reserve area, for identification and forecasting of the changes in the period August-September 1989 and 2015.

The algorithm of retrograde and modern biotope map development is as follows:

image choice;

set of standards for each of classes (biotopes);

review of a spectral histogram of specified classes for further overlapping;

overview and implementation of supervised classification;

obtaining the resulting thematic raster, transforming it into vector and manual correction of erroneous objects;

biotope areas calculation;

raster generalization and presentation in the final view ready for printing.

Decoding of Landsat satellite images was implemented using the classification method developed on artificial neural networks. During classification (accuracy of data classification is $97 \%$ on an independent sample) for each year of the research, the final image is obtained, in which each pixel is classified into one of the classes by the spectral patterns of the standards. To the input of the artificial neural network, the classifier was given a synthesized satellite image file, in which the input characteristics were data of spectral channels, and additional channels: 1) the value of normalized vegetation (NDVI), 2) water indices (NDWI), as well as a file of standards. Next, to check the separation and distribution of the training samples (standards), a "histogram analysis" of the selected types of biotopes was performed (Fedra, 2006).

On the territory of Biloozersky section of Rivne nature reserve, 10 main classes types of biotopes were selected (according to the classification system of the International Union for Conservation of Nature) as outlined in Fig. 2 below. 
Fig. 2. The biotope map of Biloozerskyi sitein Rivne nature reserve obtained as a result of Landsat 5 satellite image classification as of 08.08.2015.

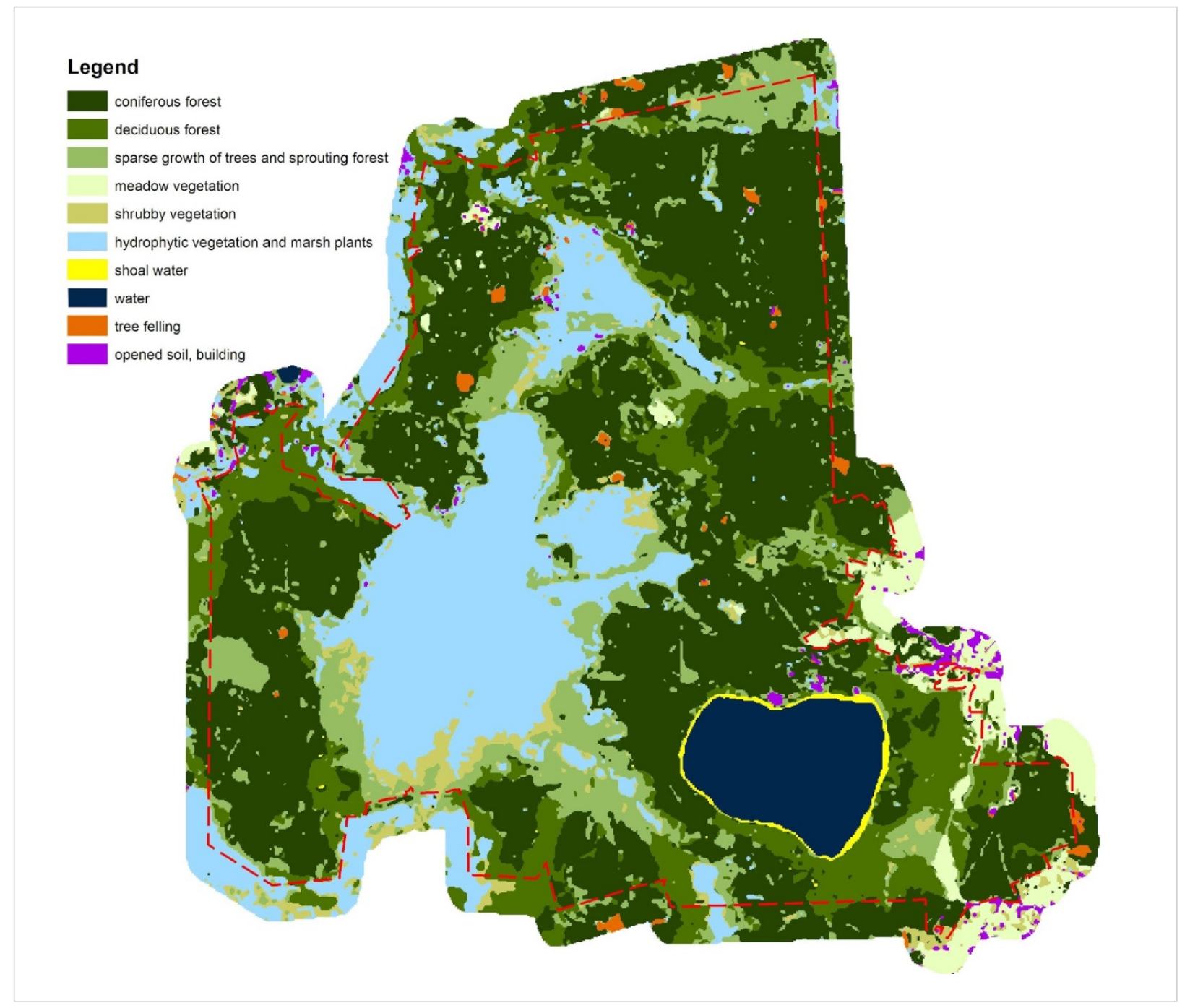

Maps of Biloozerskyi area biotopes of Rivne nature reserve were obtained for 1989 and 2015 as a result of thematic processing of remote data. Moreover, changes in the areas and distribution of the main components were identified. Calculation of the biotope area is presented in Table 1. Based on the constructed retrograde and modern biotope maps, their kinds typical for the given territory were identified. Preliminary estimation of changes which took place in their distribution was made. Thus, as of 2015 , the shallow water increased by 7.61 hectares, the water surface of the lake decreased by 4.40 hectares, the place of cutting in 1989 was not observed, and in 2015, the following areas were scanned at an area of 25.78 hectares, places of open ground and development decreased by 20.27 hectares.

All the above indicates an increase in the reforestation of Biloozerskyi site of Rivne nature reserve. The obtained results are used to determine the informative features of the environmental state, natural resource potential of the natural reserve area, the possibilities of their use in the recreational and economic complex. 
Table 1. The results of the calculation of biotope areas of the Biloozerskyi part of Rivne nature reserve (before the creation of the reserve and the current state)

\begin{tabular}{|c|c|c|}
\hline Types of biotopes, ha & 1989 & 2015 \\
\hline \multicolumn{3}{|l|}{ Woodyvegetation: } \\
\hline Coniferousforest & 3432.47 & 3609.51 \\
\hline Deciduousforest & 1246.3 & 1045.8 \\
\hline Sparsegrowthoftreesandsproutingforest & 1074.7 & 1158.48 \\
\hline Shrubbyvegetation: & 373.01 & 217.92 \\
\hline \multicolumn{3}{|l|}{ Grassyvegetation: } \\
\hline Meadowvegetation & 126.29 & 55.18 \\
\hline Hydrophytic "waterloving" vegetationandmarshplants & 1297.0 & 1453.96 \\
\hline \multicolumn{3}{|l|}{ Otherclasses: } \\
\hline Shoalwater & 32.25 & 39.86 \\
\hline Water & 427.8 & 423.38 \\
\hline Treefelling & & 25.78 \\
\hline Openedsoil, building & 41.92 & 21.64 \\
\hline The total area of the study -8051.5 ha & & \\
\hline
\end{tabular}

Fig. 3. Examples of forest clearing obtained as a result of Landsat 5 satellite image decoding as of 18.09 .1989 (a), Landsat 8 as of 08.08 .2015 (b)

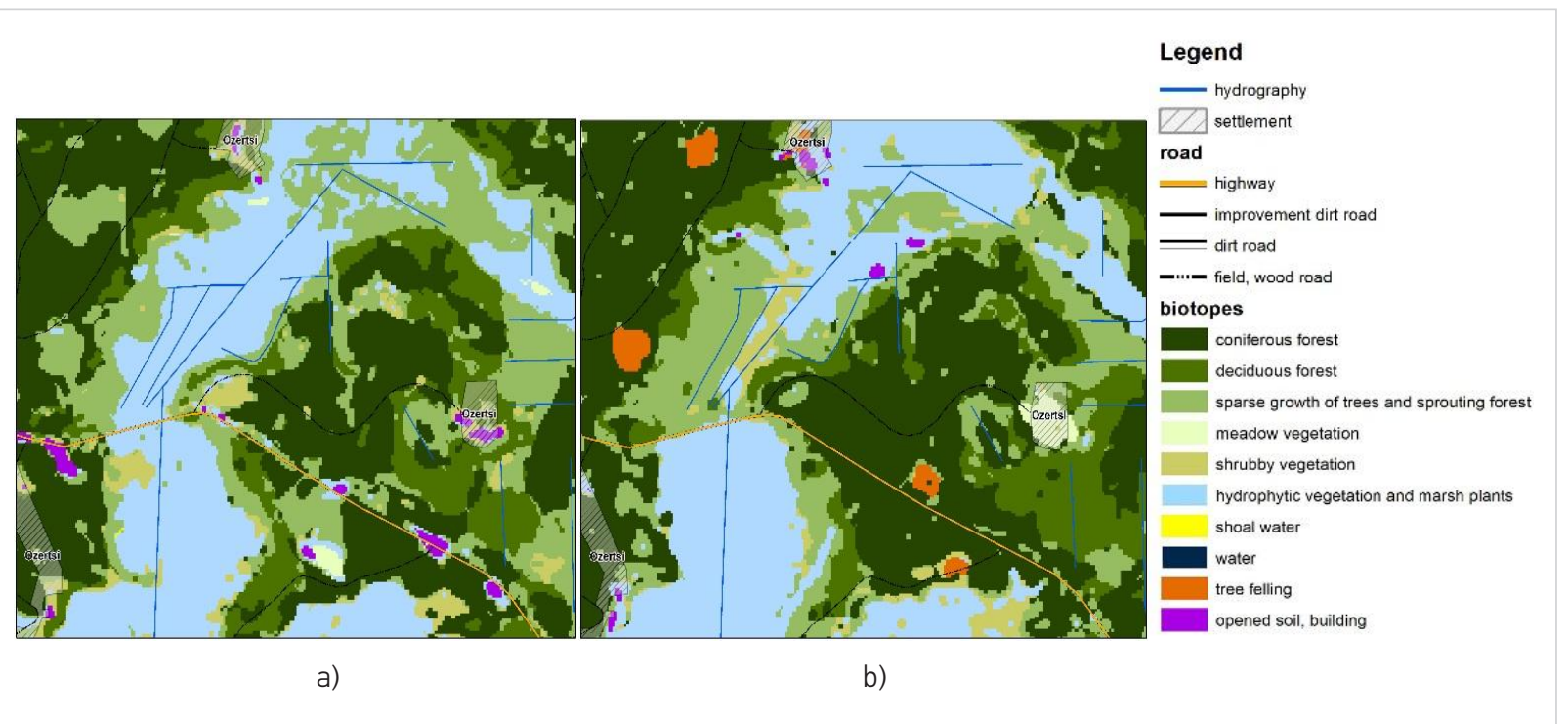


Fig. 4. Examples of a deciduous forest area reduced by means of its transformation into thin forest with bunches: a) 1989; b) 2015

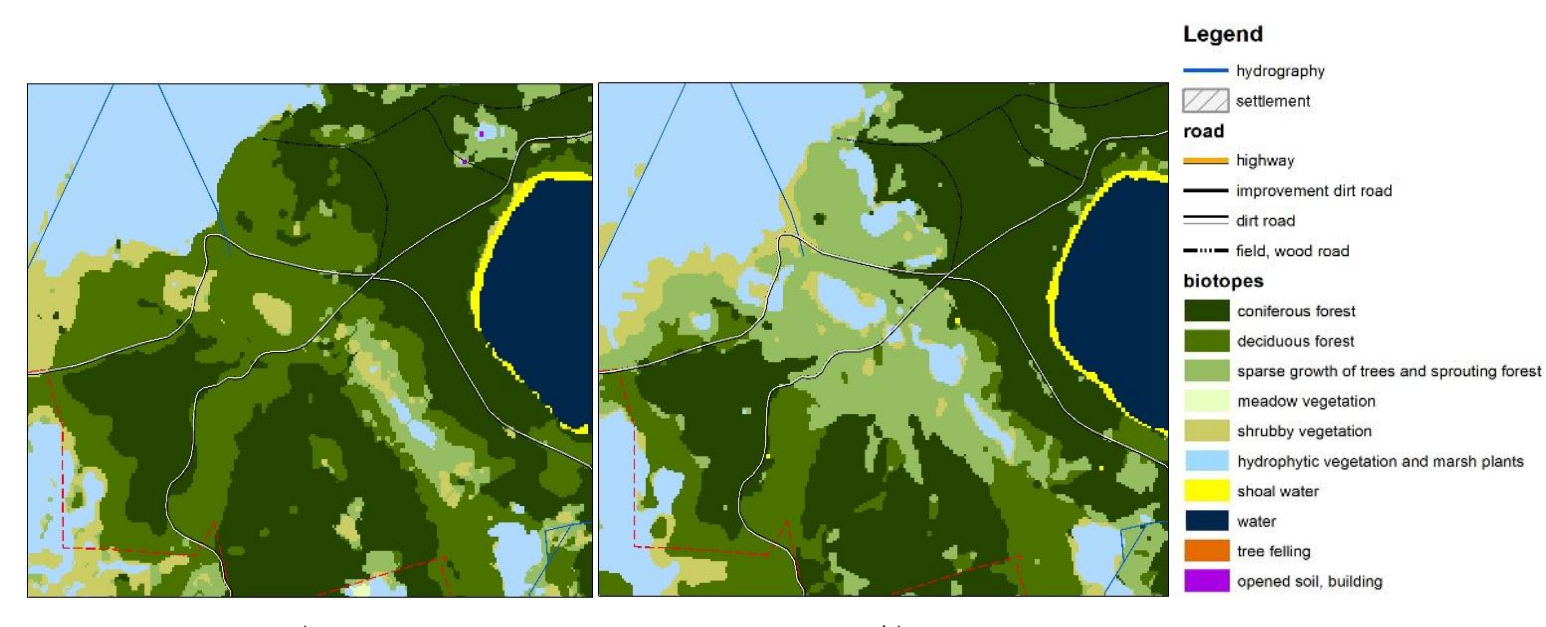

a)

b)

Fig. 5. An example of a built-up environment decrease: a) 1989; b) 2015

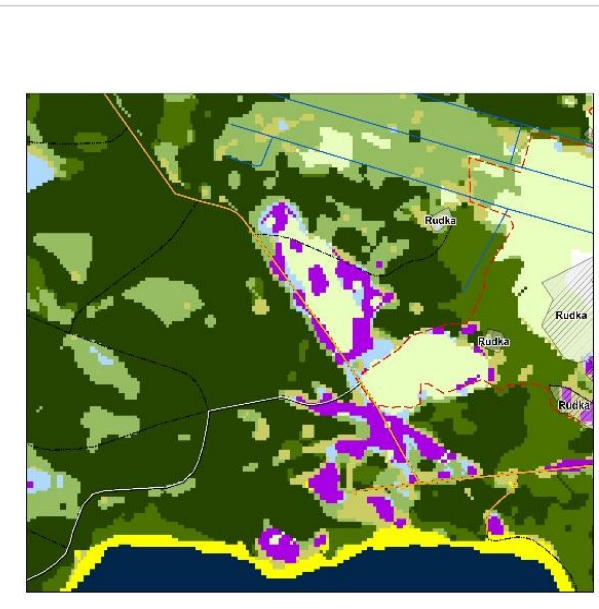

a)

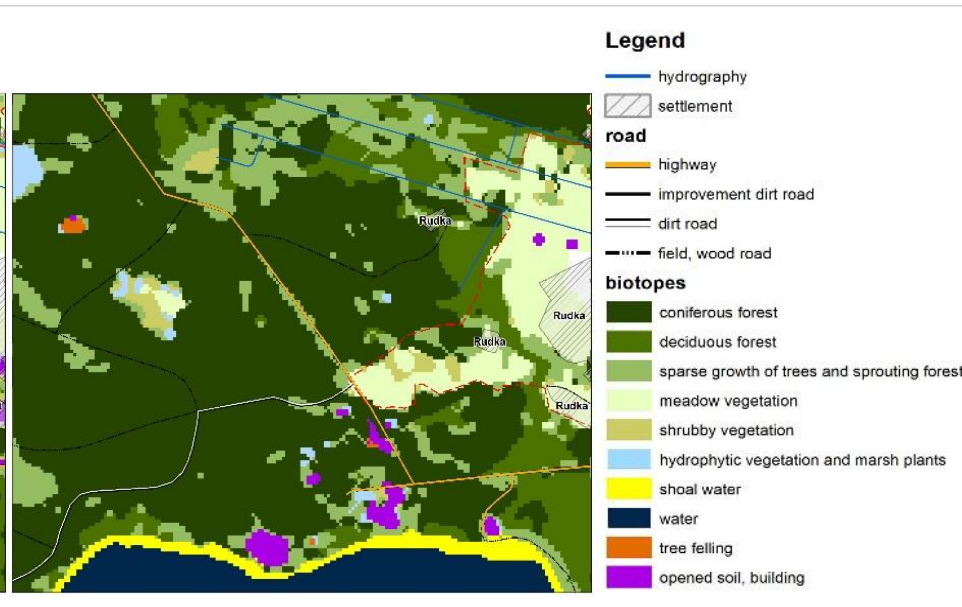

b)
Examples of biotope changes in Biloozerskyi site of Rivne nature reserve obtained as a result of Landsat satellite image decoding are presented in Figures 3-5.

Data obtained from satellite image decoding allows further evaluation of the area under study using mathematical methods and GIS technologies (Paola and Schowengerdt, 1995). All spatial information is included in the ArcGIS geodatabase. Personal geodatabase was used to store data in this system. Such data arrangement at the initial stage of GIS formation has several advantages: it allows separate creation and editing of spatial data in ArcGIS and attributive information as well. Developed actual cartographic models will clearly identify appropriate areas of the forest, help with the choice of places for recreational load and control the impact of anthropogenic factors on forest resources. 
The main thematic layers GIS of site Biloozerskyi of Rivne nature reserve were formed on the basis of the following tasks it was being developed for: cartographic layer formation according to thematic characteristic; creation and maintenance of environmental monitoring databases; processing and analysis of data obtained from field surveys in order to assess the environmental status of the territory and develop environmental measures; modeling and forecasting.

The main GIS vector layers reflect topographical features of site Biloozerskyi of Rivne nature reserve and are presented in one group. The objects that form the main vector layers were plotted to the digital topographic base by means of satellite image decoding using direct characteristics (form, size, tone and structure of the object image), using indirect characteristics (mutual arrangement of objects) and map data. In addition to image visualization, the developed cartographic model is the basis for the natural state assessment of the area under study and development of digital thematic maps within GIS environment.

In order to carry out an assessment of the protected nature reserve components, ensuring environmental safety and preventing hazardous impacts, it is necessary to analyze the state of the nature reserve area thoroughly and systematically using remotely sensed data and GIS technologies. On the basis of the obtained data, thematic layers of geospatial data were created and loaded into the geoinformation database. The developed geoinformation model will become a tool of integration of sketchy data about the object under research. These data will be based in separate thematic layers that will allow forecasting the area environmental state and will become a tool of nature reserve area management. In addition to the geographical location, natural resource potential, climatic conditions, the descriptive and analytical part of the geographic information system for assessing the territory of the nature reserve should contain data on landscape features, soil characteristics and hydrology of the study area.

The landscape site Biloozerskyi of Rivne nature reserve is mainly represented by flat and waterlogged water-glacial plain. There are 14 natural boundaries with the detailed description presented in the GIS attributive database. The surface is composed of anthropogenic fluvioglacial, alluvial and marsh-lake predominantly sandy deposits on which sod-podzol soils have been formed. Anthropogenic deposits are bedrocked with carbonate rocks of the Cretaceous and Paleogene age, which appear on the surface in some places (Fig. 6).

All spatial information is entered into the geodatabase ArcGIS. According to the results of the spatial analysis of the available attribute data, it is established that forest resources occupy the largest area on the territory under survey. Fig. 7 presents a map of the territory of the studied area on the basis of a taxonomic description of the forest area land plots as of 2015 provided by Rivne nature reserve authority's administration (Nature Records of Rivne Nature Reserve, 2015). This description takes into account the area of separate divisions with the characteristics of the forest crop and the shrub layer on the territories covered with forest vegetation. Plants and wood age and state were also taken into account. Developed cartographic models allow a detailed assessment of forest resources with the help of special ArcGIS tools using the Spatial Analyst module.

The area of Biloozerskyi site has bogs typical for the Western Polissia region and one of the largest karst lakes in Polissia. Bile lake (453 ha) and Koza-Berezyna bog are perspective to be included into the list of Ramsar Convention (Nature Records of Rivne Nature Reserve, 2015). According to calculations performed during ArcMap layer development using GIS tools and spatial analysis of available attributive data, it was found that the total wetland area of Biloozerskyi site is 2259,11 ha (Fig.8).

With the aim of prediction of changes that may occur on the nature reserve territory, field expeditionary studies were conducted on its Biloozersky site during the summer period of the maximum recreational load. As a result of mathematical calculations carried out on the basis of the data obtained, it was established that the main factors of anthropogenic impact (in order of intensity increasing) are forest fires and recreation. Despite the formally high conservation status of the area, recreational activities, which often take a spontaneous character, are permitted on some of its 
Fig. 6. The environmental map model of relief of Rivne nature reserve Biloozerskyi site

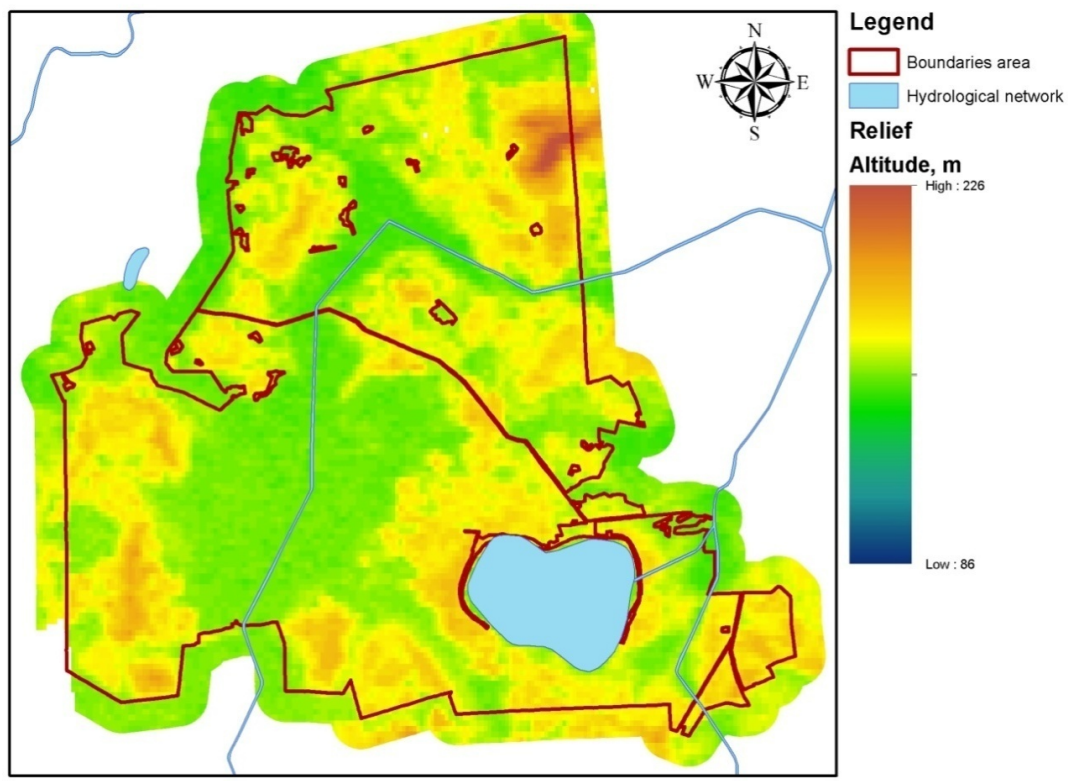

Fig. 7. The environmental map model of forest compartments of Rivne nature reserve Biloozerskyi site

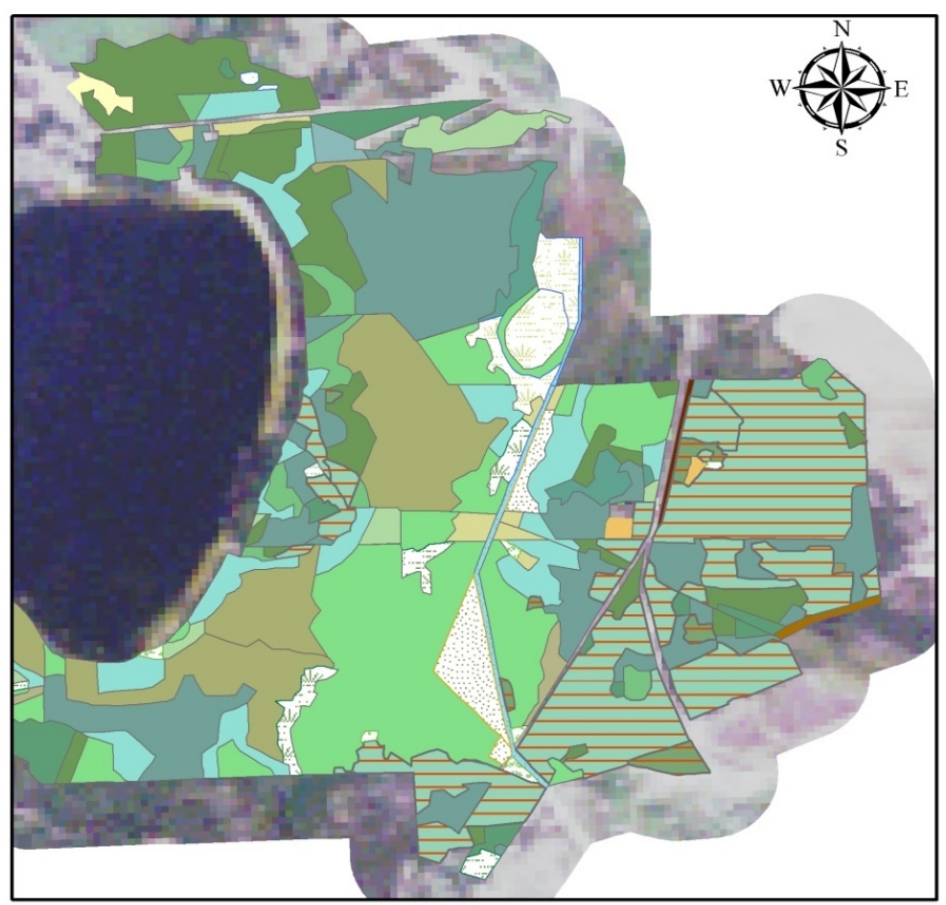

\section{Legend}

Taxation characteristics

administrative buildings/

alder black/middle-aged

alder black/ripe and overripe

alder black/ripening

alder black/young

ameliorative channe//satisfactory

arable/area forestry guard

bioglade/

birch tree/middle-aged

birch tree/ripe and overripe

birch tree/ripening

fire prevention gap/satisfactory

forest crops/not serried

forest crops/serried

forest felling/natural renewal

pine, larch/middle-aged

pine, larch/ripe and overripe

pine, larch/ripening

pine, larch/young

power line/

sands/

spruce, fir/middle-aged

swamp/

swamp/transitional poor

swamp/upper initial stage 
Fig. 8. The environmental map model of wetlands of Rivne nature reserve Biloozerskyi site

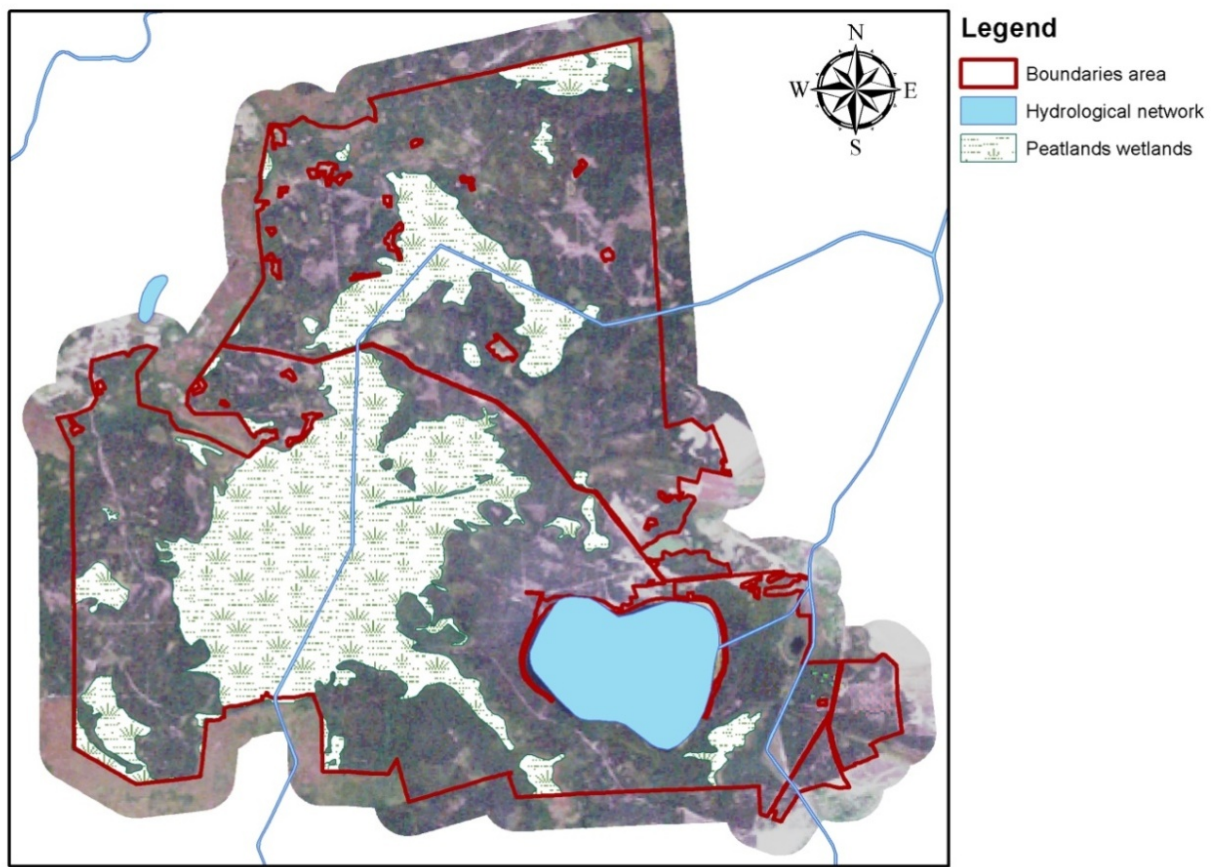

Fig. 9. The environmental map model of recreation zones of Rivne nature reserve Biloozerskyi site

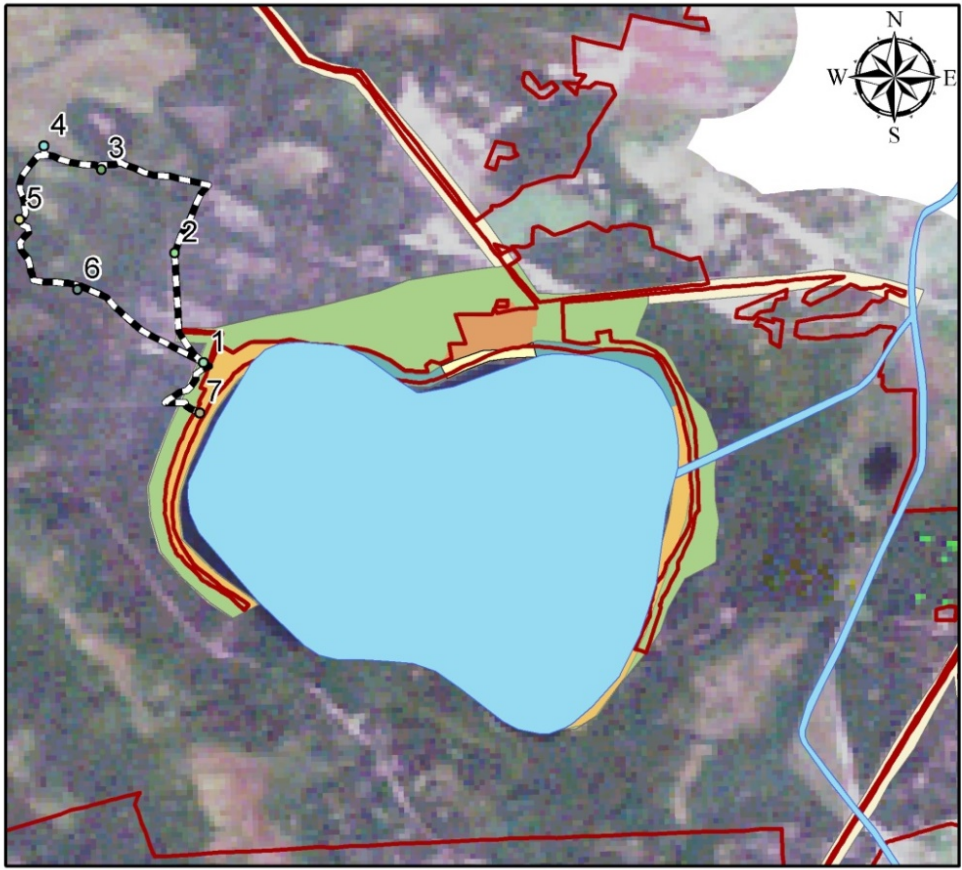

\section{Legend}

Boundaries area

Hydrological network

-.. Ecological trail

Stopping

- 1-start of excursion

- 2 - forest glade

- 3 - anthill and manger

- 4 - swamp «Koza»

- 5 - injured growing trees

- 6 - "Polesie hill"

- 7 - Lake "White"

Area of Impact Impact on the Reserve beach is all beach of campers beach of tourist base tourist base Area of Impact vehicles 
parts. In particular, it is $150 \mathrm{~m}$ of shoreline on the eastern and northern shores of the lake, as well as a strip of its water area of $50 \mathrm{~m}$ wide. For detail visualization, the data obtained are shown in Fig. 9 on a larger scale. The main recipients of the impact are wetland ecosystems, forest lands, water area and coastal zone of Bile lake. This factor creates a significant recreational load, quantitative and qualitative evaluation and regulation of the limiting scales, which is an actual scientific and applied task (Trofymchuk et al., 2015).

In addition to image visualization, the developed cartographic models are the basis for the environmental state assessment of the studied territory and compilation of a set of digital thematic maps in GIS environment. In order to carry out an assessment of the components of the protected nature reserve, to ensure environmental safety and to prevent hazardous impact, it is possible to analyze the state of the natural reserve area in detail systematically using GIS technologies. The developed cartographic models, as well as the developed database, were transferred for use to the Rivne nature reserve authorities' administration.

\section{Discussion of the research findings}

The obtained results are used to determine informative features of the environmental state, natural reserve area potential and possibilities of its use in the recreational and economic complex. It is suggested to use methodological approaches based on remote sensing / GIS technologies taking into account the status, features and specifics of protected areas for direct observation of forest and wetland landscapes.

According to the results of the protected area retrospective and modern analysis, the changes of the territory are determined and predicted. For this purpose, medium-resolution images were selected. This allowed ensuring a general accuracy of the data classification at $97 \%$ on the independent sample. The informative features and indicators of the studied ecosystem are determined as environmental status, natural resource potential, productivity of the natural ecosystem, possibility of its use in the recreational-economic complex, and the degree of recreational diversity.

The maps of biotopes of Biloozerska area of Rivne nature reserve were developed in 1989. In 2015, thematic processing of remote sensing data revealed changes in the areas and distribution of the habitat types. So, as of 2015 , the shallow water increased by 7.61 hectares, and water decreased by 4.40 hectares. In 1989, there were no places of cutting in the studied territory. In 2019, the area of 25.78 hectares was decoded. The areas of open ground and construction development decreased by 20.27 hectares, which indicates that the area of forest cover increased within the Rivne nature reserve.

The authors of the presented study used the Arclnfo / ArcGIS tools with the Spatial Analyst and ArcScene / 3Danalyst modules for visualization of the research object. The methodical scheme of the complex use of space monitoring data and field research results presented in the study are used for environmental assessment of the territory of the natural reserve area. The technology presented in the study is based on the use of a set of electronic environmental-cartographic models that contain an individual set of geospatial thematic layers in vector and raster forms, as well as attribute data in tabular and textual forms according to indicators characterizing the research object.

This structuring of data allows us to analyze the environmental state of the territory and can be used as a tool for natural and protected area management. Developed environmental-cartographic models reflect the state of the habitats of the territory, its relief, the hydrological network, recreational zones, landscapes, wetlands, digital maps of forest plantations with appropriate tax characteristics and attributive data for species requiring special protection.

\section{Conclusions}

1 The article presents methodical approaches to improving the system of background environmental monitoring, increasing its objectivity and data submission visual aspects on the basis of remotely sensed data and GIS technologies, taking into account the status, characteristics and specifics of protected areas. It is proposed to use information analytical technologies of remotely sensed data processing to conduct research on the dynamics of changes in the state of natural territories, which are grounded on decrypting of satellite images using the method of artificial neural network. 
2 Tools integrated in ArcGis are used for collection, accumulation, processing, formalization and presentation of data regarding impact factors and the environmental ecosystem state. The above tools provide for interpretation of analysis results in the graph form on electronic maps and implementation of mathematical methods for assessment of intensity of the anthropogenic impact and modeling of its environmental consequences. Synthesized interactive cartographic materials are created with the help of modern information technology of geodata analysis, have high visibility and can be updated with further use by environmental institutions.

3 The practical application of the results can be used in the development of environmental networks, the main purpose of which is to ensure the preservation of bio-and landscape diversity, the implementation of background environmental monitoring,

\section{References}

Armenakis C., Siekierska E. (2009) Visualization of spatio-temporal change, Manual of Geographic Information Systems, Ed. M. Madden, American Society for Photogrammetry and Remote Sensing, Chapter 23, 395-412.

Armenakis C., Nirupama N., Zalidis G., Alexandridis T. (2014) Degradation of coastal wetlands using examples from Greece and Canada: A review. International Journal of Ecology \& Development, 29(3), 87-109.

Dovgyi S.O., KrasovskiyH.Ya.,Radchuk V.V., Trofimchuk O.M. and others (2018) Geomodels in environmental and economic land assessment tasks: Monography. 256.

Dovhyi S. O., Lialko V. I., Trofymchuk O. M., Fedorovskyi O. D. (2001) Informatization of aerospace geography. Kyiv: Nauk. Dumka, Ukraine, 606.

Fedra K. (2006) Beyond GIS: Integrating dynamic simulatiom models and GIS for natural resources and environmental management, In: Map Midle East, Proceedings, 10.

Fedra K. (2006) Embedded GIS in environmental management, GIS Development, Vol 7, 7/3, 22-16.

Jonson K.,Khoef D.M., Kryvoruchko K., Lukas N. (2002) ArcGisGeostatistical Analyst. User guide: Transl. From Eng. International Journal of Remote Sensing, 278. stabilization of environmental balance, increasing of landscape productivity, improvement of the environment and provision of environmental safety of nature reserve fund territories. The results obtained as a whole can be used by administrative authorities of environmental institutions, the department of the environmental network and the nature reserve fund, as well as for public environmental control.\{Gurauskiene, 2006, Eco-design methodology for electrical and electronic equipment industry\}

\section{Acknowledgements}

We would like to thank the director of the Rivne nature reserve Bachuk V.A. and the employee of the Rivne nature reserve Zhuravchik R.A. for his helpful guidance, consultations, and support in field research.
Nature records of Rivne Nature Reserve. - Books 1-3. Sarny, 2015. Korchenko O., Pohrebennyk V., Gancarczyk J., Sheviakina N., Zagorodnia S. (2019) Use of modern information technologies for and management of nature reserve areas. International multidisciplinary scientific geoconference SGEM 2019 - Albena, Bulgaria, 697-703. https://doi.org/10.5593/sgem2019/2.1/S07.091

Paola J.D., Schowengerdt R.A. (1995) Geoscience Remote Sensing, IEEETrans, 33, 981-996. https://doi.org/10.1109/36.406684

Tomchenko O.V. (2015) Substantiation of wetland system analysis methods using remote sensing data and ground observations (in the upper Kyiv reservoir case study): Abstract. Dis. ... candidate. Sc. Science, Spec. 05.07.12 - remote aerospace research, Kyiv, Scientific Centre for Aerospace Research of the Earth National Academy of Sciences of Ukraine, 22.

Trofymchuk O., Trysnyuk V., Novokhatska N., Radchuk I. (2014) Geoinformation technologies in decision issues of municipal solid waste, J. Environ. Sci. and Engineering, Vol. A3,183-187.

Trofymchuk O., Kreta D., Myrontsov M., Okhariev V., Shumeiko V., Zagorodnia S. (2015) Information Technologyin Environmental Monitoringfor Territorial system Ecological Assessment, J. Environ. Sci. and Engineering, A4, 79-84. https://doi. org/10.17265/2162-5298/2015.02.003

This article is an Open Access article distributed under the terms and conditions of the Creative Commons Attribution 4.0 (CC BY 4.0) License (http://creativecommons.org/licenses/by/4.0/ ). 